\title{
Cost-effectiveness of telemonitoring screening for diabetic foot ulcer: a mathematical model
}

\author{
Chris Boodoo BSc, Julie A. Perry PhD, General Leung PhD, Karen M. Cross MD PhD, \\ Wanrudee Isaranuwatchai $\mathrm{PhD}$
}

\section{Abstract}

Background: One of the most common (and costly) complications of diabetes are diabetic foot ulcers, which often result in lowerextremity amputation. Regular foot care can reduce complications; however, roughly half of Canadians with diabetes do not participate in screening. We sought to evaluate the economic effects of using telemonitoring for diabetic foot ulcer prevention using mathematical modelling.

Methods: We used Markov modelling to compare current screening standards (standard care) to population-wide and targeted (highrisk) telemonitoring programs in a hypothetical cohort of Canadian patients aged 60 years. We varied the effectiveness (or outcome), defined as the proportion of diabetic foot ulcers prevented, to explore cost-effectiveness using model parameters from published literature and clinical experts.

Results: At 20\%-40\% effectiveness, population-based prevention resulted in 0.00399-0.00790 quality-adjusted life years (QALYs) gained per person over 5 years and an incremental cost of $\$ 479-\$ 402$ compared to standard care. At $15 \%-40 \%$ effectiveness, highrisk prevention resulted in a cost decrease per person over 5 years $(\$ 1.26-\$ 25.55)$, with health benefits of 0.000207-0.00058 QALYs gained.

Interpretation: The use of telemonitoring in the diabetic lower extremity can offer patients better quality of life and can be costeffective compared to current Canadian screening practices. Future work should focus on developing and validating technologies based on objective outcome measures for remote monitoring of the diabetic foot.

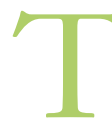
he management and care of foot ulcers impose a tremendous burden on patients with diabetes and decrease their quality of life. ${ }^{1}$ Moreover, rates of lower-extremity amputation are 22 times higher among people with diabetes who have a foot ulcer than among the general population. ${ }^{2} \mathrm{Up}$ to $85 \%$ of ulcer-related lower-extremity amputation procedures are preventable with frequent monitoring and prompt treatment. ${ }^{3-5}$ However, only $51 \%$ of Canadians with diabetes had a foot screen in $2009,{ }^{6}$ and foot care services essential to ulcer prevention such as chiropody and orthotic foot care are not funded in Ontario's health care system. ${ }^{7}$ This gap in care has led to sporadic prevention efforts and delayed care. ${ }^{8}$ Some barriers to frequent screening and monitoring such as travel distance, time limitations and unorganized referrals to specialists can be overcome by using technology to make medical services more accessible (known as telemedicine). Telemedicine is an increasingly popular mechanism for remote monitoring of chronic conditions and has been used successfully in diabetic populations to monitor (and decrease) hemoglobin $A_{1 c}$ levels, increase inpatient understanding of diabetes and improve cohesion among members of health care teams. ${ }^{9-12}$ Currently, there is mixed evidence on the effectiveness of telemedicine for monitoring diabetic foot ulcers, largely owing to a lack of large controlled studies. ${ }^{13-24}$ Several technologies designed to diagnose ulcers have recently been developed and could potentially complement a telemedicine-based monitoring program. ${ }^{25-27}$

As the Canadian population ages, the strategic allocation of resources in our health care system becomes increasingly important. The global prevalence of diabetes is currently $8.5 \%$

Competing interests: General Leung and Karen Cross have an equity interest in a company developing a diabetic foot ulcer telemonitoring device. No other competing interests were declared.

This article has been peer reviewed.

Correspondence to: Wanrudee Isaranuwatchai, isaranuwatcw@smh.ca CMAJ Open 2018. DOI:10.9778/cmajo.20180088 
(up from $4.8 \%$ in 1980) and is expected to increase. ${ }^{28}$ By 2020 , an estimated 3.7 million Canadians will have diabetes, with an associated cost of nearly $\$ 17$ billion. ${ }^{29}$ Diabetes accounted for $3.5 \%$ of Canadian health care spending in 2005, ${ }^{29}$ including an estimated \$547 million on diabetic foot ulcer care, or \$21371 per prevalent case. ${ }^{30}$ The cost of a single ulcer case was $\$ 52$ 360, which included costs of hospital admissions, emergency department and clinic visits, drugs, dressings, and home and long-term care. ${ }^{30}$ Health care systems, which have traditionally been treatment-oriented and less focused on prevention, must adapt to meet increased demands and costs. Although multidisciplinary efforts were found to improve patient outcomes, ${ }^{31}$ the success of these initiatives is dependent on scale of resource allocation, additional personnel and coordination of diverse clinical teams including podiatrists, infectious disease specialists and plastic surgeons. ${ }^{7,32}$ The lack of evidence for the efficacy of these specialized early-intervention programs makes funding them difficult from a policy-making perspective. ${ }^{33,34}$ This study aimed to explore the preliminary cost-effectiveness of a telemedicine intervention for the prevention of diabetic foot ulcers. Specifically, we sought to determine the effectiveness threshold at which telemedicine prevention efforts could be cost-effective in Canada.

\section{Methods}

Analysis and reporting were done according to Canadian Agency for Drugs and Technologies in Health guidelines and Consolidated Health Economic Evaluation Reporting Standards. ${ }^{35,36}$

\section{Comparators}

\section{Intervention}

The intervention was telemedecine by means of a device used to monitor the feet of people with diabetes remotely, based on number of annual visits to physicians recommended by the International Working Group on the Diabetic Foot (Supplementary Table A1, Appendix 1, available at www.cmajopen.ca/ content/6/4/E486/suppl/DC1). ${ }^{4,37}$ We defined 2 approaches: a high-risk intervention (telemedicine device given to patients after their first diabetic foot ulcer) and a population-based intervention (device given before the formation of an ulcer).

\section{Standard care in Canada (control)}

We defined standard care in our cohort as the number of annual in-person visits to a physician, as recommended by the International Working Group on the Diabetic Foot and the Canadian Association of Wound Care. ${ }^{4,37}$ We adjusted the number of visits per patient to the proportion of Canadians who received a foot screen in $2009(51 \%){ }^{6}$

\section{Cohort and time horizon}

The hypothetical cohort consisted of Canadians aged 60 years with diabetes and no history of ulceration. The cycle length was 4 months (the average time to ulcer healing ${ }^{38}$ ), and the time horizon was 5 years.

\section{Model}

We used a Markov model to simulate the history of diabetic foot ulcers in Canada using Microsoft Excel version 15.41 (Figure 1). The model was debugged to validate functionality (see Appendix 1 for details). Cohort members started in state 1 (person with diabetes) and moved into predefined health states in 4-month cycles for 5 years. Each state had a 4-month cost estimate, and costs accumulated with time. Model validation is outlined in more detail in Appendix 1.

\section{Effectiveness}

We varied the effectiveness of primary prevention efforts from $5 \%$ to $40 \%$ at 3 possible states - low risk for ulcer formation, moderate risk for ulcer formation and healed ulcer ${ }^{33}$ - based on expert clinical opinion. We defined effectiveness as a decrease in the number of ulcers. The transition from a healed ulcer state to a recurrent ulcer state was decreased by $5 \%-40 \%$ (high-risk approach), and the transition from a lowrisk, moderate-risk or healed ulcer state to an ulcer state was decreased by $5 \%-40 \%$ (population-based approach).

\section{Model parameters and outcomes}

Model parameters are listed in Table 1 and Supplementary Table A2, Appendix 1. Outcomes were expressed in qualityadjusted life years (QALYs). ${ }^{54}$ Values were based on a review of utility values for type 2 diabetes $^{48}$ (Supplementary Table A2, Appendix 1). We used $\beta$ distributions for all utility values, with a $1.5 \%$ discount rate. ${ }^{35,54}$ Outcomes from our analysis were expressed as QALYs and incremental costeffectiveness ratios (ICERs) (which incorporate both the difference in costs between comparators in the numerator and the difference in QALYs in the denominator).

\section{Resource use and costs}

Costs and corresponding sources are listed in Table $1 . .^{50,51} \mathrm{We}$ used $\gamma$ distributions for all cost parameters, with $1.5 \%$ discount rate reported in 2015 Canadian dollars. ${ }^{35,54}$ Details regarding how we derived costs are provided in Appendix 1. The cost of the telemedicine device was incurred once, and the cost of the telemedicine service was incurred every 4 months. The cost of diabetes was not included in this analysis.

\section{Analysis}

We explored cost-effectiveness by varying telemedicine effectiveness and comparing results to the standard-care model. We conducted separate analyses for the populationbased and high-risk approaches compared to the standardcare model. We calculated the ICER as the difference in cost divided by the difference in effectiveness. We calculated the difference in cost and in effectiveness as the cost or effectiveness of the intervention less the cost or effectiveness of standard care.

\section{Probabilistic sensitivity analysis}

We conducted Monte Carlo simulations of 1000 trials for both approaches versus standard care. We used $\gamma$ distributions 


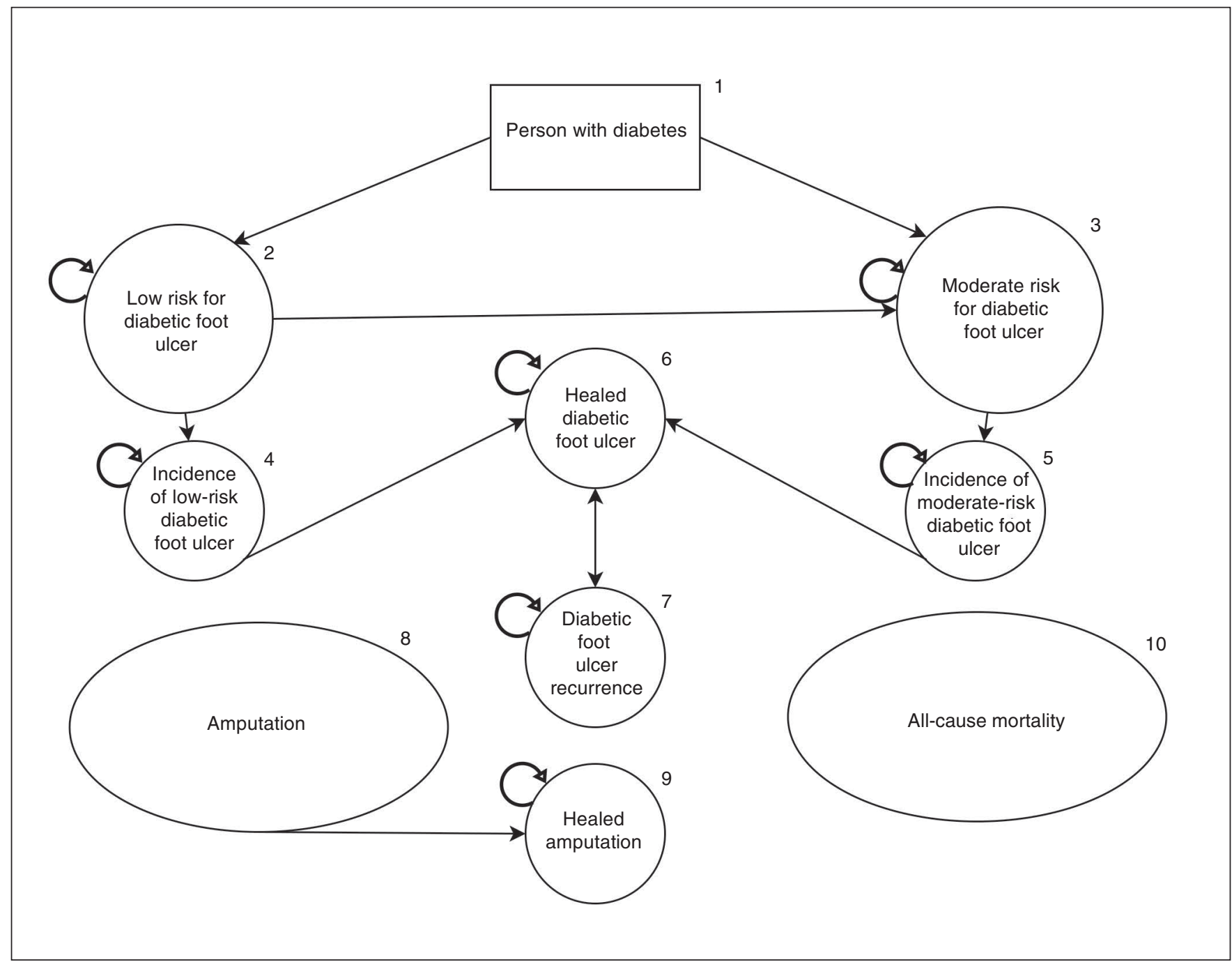

Figure 1: Markov model of diabetic foot ulcer incidence and progression. All states can also transition to the amputation state, and all states can be absorbed by the death state (not shown). See Appendix 1 for details on each health state.

for cost parameters and $\beta$ distributions for utility values. We used Dirichlet distributions for all multinomial transition parameters and $\beta$ distributions for binomial transition parameters. ${ }^{54}$ At $30 \%$ effectiveness, we compared the probabilistic sensitivity analysis results for the high-risk and populationbased approaches on a cost-effectiveness plane. We constructed cost-effectiveness acceptability curves, with willingness-to-pay thresholds of $\$ 0-\$ 100000$. A variation of the cost-effectiveness acceptability curve was also used. We identified proportions of simulations resulting in costeffectiveness at varying effectiveness levels for specific willingness-to-pay thresholds.

We conducted 1-way analyses to explore the effect on ICERs when key parameters were varied based on data in the literature and expert opinion (see Appendix 1 for details).

\section{Ethics approval}

No ethics approval was required as the study did not involve human subjects.

\section{Results}

\section{Population-based approach}

A population-based approach to monitoring the feet of diabetic patients was both costlier and more effective than standard care (Table 2). When effectiveness of the telemedicine intervention increased, QALYs gained increased, and incremental costs decreased. If adopting a population-based approach decreased ulcer incidence by $20 \%-40 \%$, the resulting health benefit was 0.00399-0.00790 QALYs gained per person. A population-based approach using telemedicine was a more widespread screening strategy than is currently in place in Canada, which translated into incremental costs of \$479-\$402 per person and ICERs of \$120 087-\$50 915.

\section{High-risk approach}

People with diabetes who have had an ulcer are more likely than other people with diabetes to experience subsequent ulcers. Our second approach took this into account. We found 


\begin{tabular}{|c|c|c|}
\hline Variable/state & Value (range) & Source \\
\hline \multicolumn{3}{|l|}{ Transition probability, \% } \\
\hline $\begin{array}{l}\text { Rate of development of low-risk diabetic } \\
\text { foot ulcer }\end{array}$ & $0.3(0.3-0.41)$ & Lavery et al. ${ }^{39}$ \\
\hline $\begin{array}{l}\text { Rate of development of moderate-risk } \\
\text { diabetic foot ulcer }\end{array}$ & $0.45(0.45-2.18)$ & Lavery et al..$^{39}$ \\
\hline $\begin{array}{l}\text { Rate of development of recurrent } \\
\text { diabetic foot ulcer }\end{array}$ & $11.21(7.17-15.66)$ & Armstrong et al. ${ }^{40}$ Dubský et al. ${ }^{41}$ \\
\hline $\begin{array}{l}\text { Healing rate for low-risk diabetic foot } \\
\text { ulcer }\end{array}$ & 45.71 & Prompers et al. ${ }^{42}$ \\
\hline $\begin{array}{l}\text { Healing rate for moderate-risk diabetic } \\
\text { foot ulcer }\end{array}$ & 32.32 & Prompers et al. ${ }^{42}$ \\
\hline $\begin{array}{l}\text { Healing rate for recurrent diabetic foot } \\
\text { ulcer }\end{array}$ & 11.51 & Örneholm et al. ${ }^{43}$ \\
\hline $\begin{array}{l}\text { Amputation rate for low-risk diabetic foot } \\
\text { ulcer }\end{array}$ & $0.67(0.3-0.77)$ & Lavery et al.,, ${ }^{39}$ Prompers et al., ${ }^{42}$ Moulik et al. ${ }^{44}$ \\
\hline $\begin{array}{l}\text { Amputation rate for moderate-risk } \\
\text { diabetic foot ulcer }\end{array}$ & $2.74(0.063-8.54)$ & $\begin{array}{l}\text { Lavery et al.. }{ }^{39} \text { Prompers et al., }{ }^{42} \text { Morbach } \\
\text { et al., }{ }^{45} \text { Oyibo et al. }{ }^{46}\end{array}$ \\
\hline $\begin{array}{l}\text { Amputation rate for recurrent diabetic } \\
\text { foot ulcer }\end{array}$ & $3.45(0.68-3.45)$ & Lavery et al., ${ }^{39}$ Örneholm et al. ${ }^{43}$ \\
\hline $\begin{array}{l}\text { Mortality rate for low-risk diabetic foot } \\
\text { ulcer }\end{array}$ & $1.17(1.01-2.73)$ & Prompers et al., ${ }^{42}$ Morbach et al. ${ }^{45}$ \\
\hline $\begin{array}{l}\text { Mortality rate for moderate-risk diabetic } \\
\text { foot ulcer }\end{array}$ & $3.26(3.26-8.07)$ & Prompers et al. ${ }^{42}$ Morbach et al. ${ }^{45}$ \\
\hline $\begin{array}{l}\text { Mortality rate for recurrent diabetic foot } \\
\text { ulcer }\end{array}$ & $3.26(3.26-8.07)$ & $\begin{array}{l}\text { Prompers et al., }{ }^{42} \text { Örneholm et al., }{ }^{43} \text { Morbach } \\
\text { et al. }{ }^{45}\end{array}$ \\
\hline Mortality rate for amputation & $\begin{array}{l}\text { See Supplementary Figure } \\
\text { A3, Appendix } 1\end{array}$ & Aulivola et al. ${ }^{47}$ \\
\hline \multicolumn{3}{|l|}{ Utility/cost* } \\
\hline No ulcer & $0.7850(0.681-0.889)$ & Beaudet et al. ${ }^{48}$ \\
\hline Active diabetic foot ulcer & $0.615(0.578-0.652)$ & Beaudet et al. ${ }^{48}$ \\
\hline Healed diabetic foot ulcer & 0.680 & Redekop et al. ${ }^{49}$ \\
\hline Amputation & $0.505(0.396-0.615)$ & Beaudet et al. ${ }^{48}$ \\
\hline Initial screen, \$ & 60.00 & $\begin{array}{l}\text { Ontario Ministry of Health and Long-Term } \\
\text { Care }^{50}\end{array}$ \\
\hline At low risk for diabetic foot ulcer, $\$$ & 67.80 & $\begin{array}{l}\text { Ontario Ministry of Health and Long-Term } \\
\text { Care }^{50}\end{array}$ \\
\hline $\begin{array}{l}\text { At moderate risk for diabetic foot ulcer, } \\
\$\end{array}$ & 85.87 & $\begin{array}{l}\text { Ontario Ministry of Health and Long-Term } \\
\text { Care }\end{array}$ \\
\hline Diabetic foot ulcer, $\$$ & 2395.75 & $\begin{array}{l}\text { Ontario Ministry of Health and Long-Term } \\
\text { Care, }{ }^{50} \text { Canadian Institute for Health } \\
\text { Information }\end{array}$ \\
\hline Amputation, \$ & 16752.15 & $\begin{array}{l}\text { Ontario Ministry of Health and Long-Term } \\
\text { Care, }{ }^{50} \text { Canadian Institute for Health } \\
\text { Information }{ }^{51}\end{array}$ \\
\hline Healed amputation, \$ & 78.40 & $\begin{array}{l}\text { Ontario Ministry of Health and Long-Term } \\
\text { Care, }{ }^{50} \text { Canadian Institute for Health } \\
\text { Information }{ }^{51}\end{array}$ \\
\hline Healed diabetic foot ulcer, $\$$ & 135.60 & $\begin{array}{l}\text { Ontario Ministry of Health and Long-Term } \\
\text { Care }{ }^{50}\end{array}$ \\
\hline Telemedicine device, $\$$ & 20.00 & Fasterholdt et al. ${ }^{52}$ \\
\hline Telemedicine service, $\$$ & 14.65 & Ontario Telemedicine Network ${ }^{53}$ \\
\hline
\end{tabular}




\begin{tabular}{|c|c|c|c|c|c|c|}
\hline $\begin{array}{l}\text { RR for } \\
\text { development of } \\
\text { diabetic foot ulcer }\end{array}$ & $\begin{array}{c}\text { Effectiveness, } \\
\%^{*}\end{array}$ & QALYs & Cost, \$† & $\begin{array}{c}\text { Incremental } \\
\text { cost, } \$ \dagger\end{array}$ & $\begin{array}{l}\text { Incremental } \\
\text { effect, QALYs }\end{array}$ & $\begin{array}{c}\text { Incremental } \\
\text { cost-effectiveness } \\
\text { ratioł }\end{array}$ \\
\hline \multicolumn{7}{|c|}{ Standard-care approach } \\
\hline 1.00 & 0 & 3.650710 & 732.42 & - & - & - \\
\hline \multicolumn{7}{|c|}{ High-risk approach } \\
\hline 0.95 & 5 & 3.650777 & 740.12 & 7.70 & 0.000067 & 114017.16 \\
\hline 0.90 & 10 & 3.650847 & 735.69 & 3.27 & 0.000136 & 239864.99 \\
\hline 0.85 & 15 & 3.650917 & 731.16 & -1.26 & 0.000207 & Dominant \\
\hline 0.80 & 20 & 3.650987 & 726.53 & -5.89 & 0.000278 & Dominant \\
\hline 0.75 & 25 & 3.651060 & 721.78 & -10.63 & 0.000351 & Dominant \\
\hline 0.70 & 30 & 3.651137 & 716.93 & -15.49 & 0.000426 & Dominant \\
\hline 0.65 & 35 & 3.651210 & 711.96 & -20.46 & 0.000502 & Dominant \\
\hline 0.60 & 40 & 3.651290 & 706.87 & -25.55 & 0.000580 & Dominant \\
\hline \multicolumn{7}{|c|}{ Population-based approach } \\
\hline 0.95 & 5 & 3.651713 & 1272.41 & 539.99 & 0.00100 & 538425.36 \\
\hline 0.90 & 10 & 3.652710 & 1252.67 & 519.25 & 0.00200 & 259406.24 \\
\hline 0.85 & 15 & 3.653767 & 1231.25 & 498.83 & 0.00300 & 166490.29 \\
\hline 0.80 & 20 & 3.654697 & 1211.17 & 478.75 & 0.00399 & 120103.31 \\
\hline 0.75 & 25 & 3.655680 & 1191.43 & 459.01 & 0.00497 & 92330.60 \\
\hline 0.70 & 30 & 3.656667 & 1172.06 & 439.64 & 0.00595 & 73867.36 \\
\hline 0.65 & 35 & 3.657637 & 1153.07 & 420.65 & 0.00693 & 60725.94 \\
\hline 0.60 & 40 & 3.658606 & 1134.48 & 402.06 & 0.00790 & 50912.60 \\
\hline $\begin{array}{l}\text { Note: } Q A L Y=\text { quality-ac } \\
\text { *Proportion of ulcers pr } \\
\text { †2015 Canadian dollars } \\
\text { fDominant = less costl }\end{array}$ & $\begin{array}{l}\text { ted life year, RR = } \\
\text { ted. } \\
\text { d more effective. }\end{array}$ & ve risk. & & & & \\
\hline
\end{tabular}

that screening a high-risk population was slightly less costly and more effective than standard care at $15 \%$ effectiveness (Table 1). As expected, when effectiveness of ulcer prevention increased, there was also an increase in cost savings and QALYs gained. Over 5 years with effectiveness of $15 \%-40 \%$, the health benefit was $0.000207-0.00058$ QALYs gained per person, whereas costs decreased by $\$ 1.26-\$ 25.55$ per person.

\section{Sensitivity analysis}

The majority of Monte Carlo simulations for the populationbased approach resulted in more QALYs gained and higher costs since more people were screened (Figure 2). We also found that some simulations for both approaches resulted in fewer QALYs gained than the standard-care model, which is attributable to uncertainty in utility values. The costs in these cases were consistent with simulations that resulted in QALYs gained. We also conducted Monte Carlo simulations for all models (see Appendix 1 for details).

\section{Identifying highest probability of cost-effectiveness}

Although the population-based approach prevented more ulcers, resulting in more QALYs gained, the cost of imple- menting such an approach is intuitively higher. To determine which intervention was more likely to have a lower ICER, we calculated the probability of cost-effectiveness for both approaches at 30\% effectiveness. The results showed that a high-risk screening strategy had a higher probability than the population-based approach of being cost-effective at all willingness-to-pay thresholds (Figure 3). At a threshold of $\$ 50000$, the high-risk and population-based approaches had a probability of cost-effectiveness of $92 \%$ and $25 \%$, respectively. At a threshold of $\$ 100000$, the corresponding probability values were $86 \%$ and $60 \%$. We next varied effectiveness levels at defined willingness-to-pay thresholds (Figure 4). Not surprisingly, increasing the effectiveness of the intervention increased the probability of cost-effectiveness for both the high-risk and the population-based approach.

Further analyses summarizing the effects of varying parameters related to cost of telemedicine, foot ulcer state utility values and ulcer incidence rates can be found in Supplementary Figures A1 and A2, Appendix 1. Influential parameters were utility values for healed ulcers, active ulcers and no history of ulceration, and incidence rates for low-risk, moderate-risk and recurrent ulcers. 


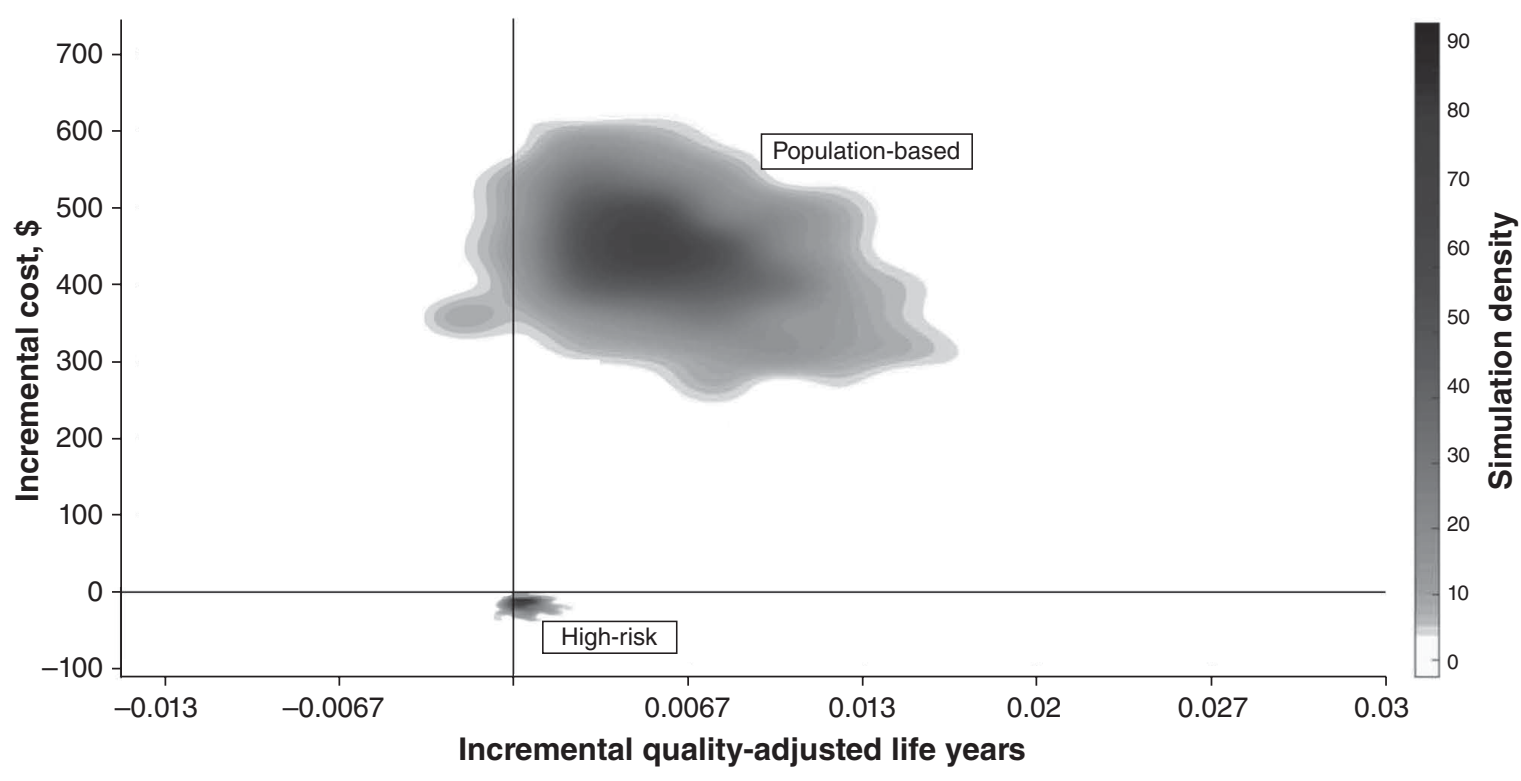

Figure 2: Cost-effectiveness plane of 1000 Markov simulations in both a high-risk approach and a population-based approach assuming a rate of effectiveness of diabetic foot ulcer prevention of $30 \%$. Most of the simulations conclude that telemedicine screening results in a gain of quality-adjusted life years, whereas only the high-risk screening strategy results in cost savings to the health care system.

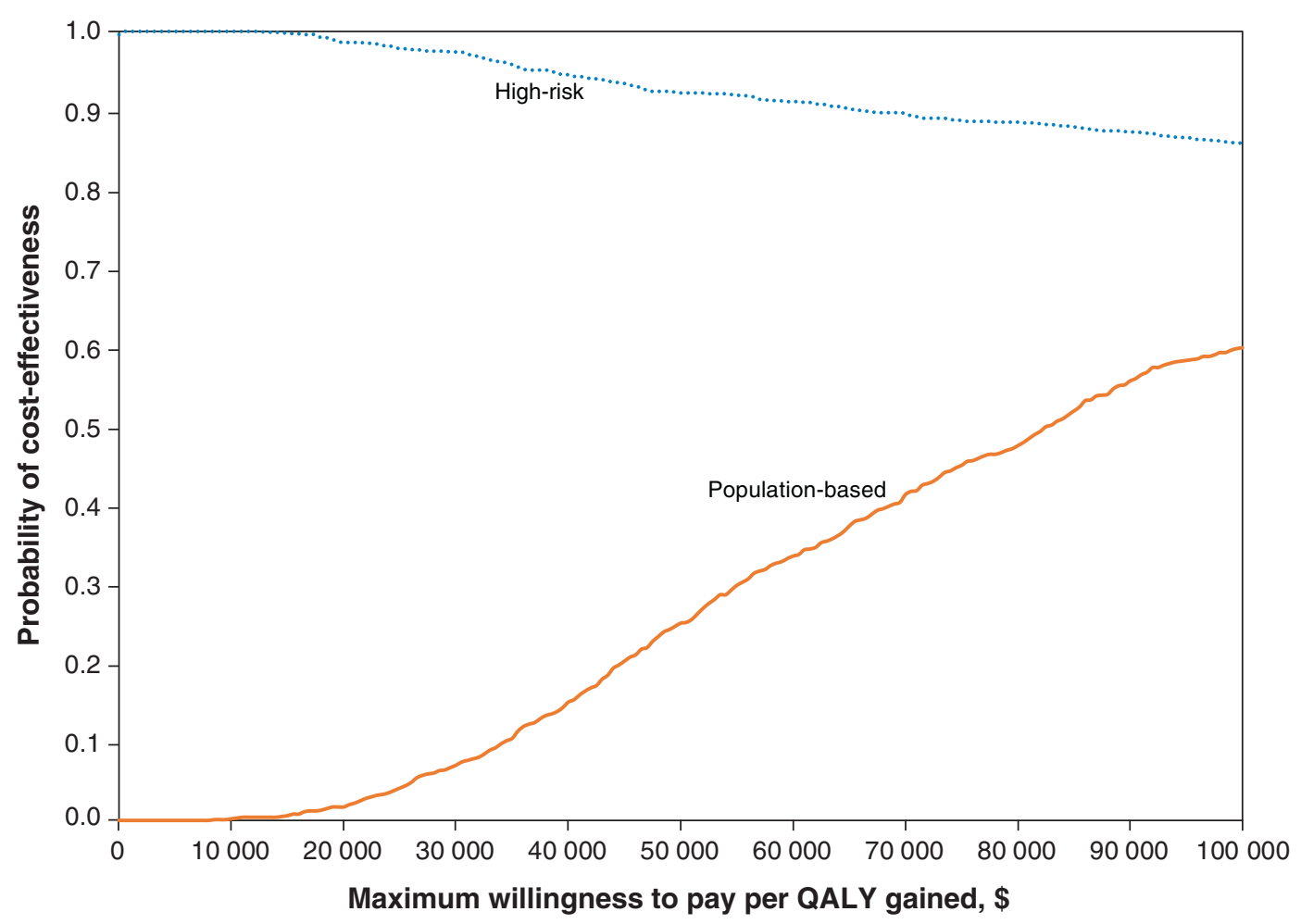

Figure 3: Cost-effectiveness acceptability curve, which summarizes the impact of uncertainty on the results, showing the proportion of simulations that resulted in an incremental cost-effectiveness ratio less than a willingness-to-pay threshold (x-axis) for the high-risk and populationbased approaches at 30\% effectiveness. These proportions can be interpreted as probability of cost-effectiveness, based on 1000 simulations. Note: QALY = quality-adjusted life year. 
A

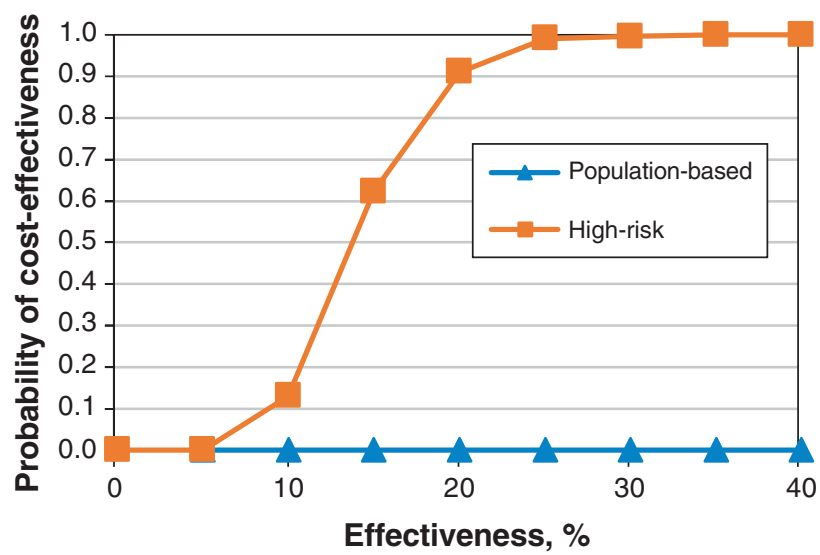

C

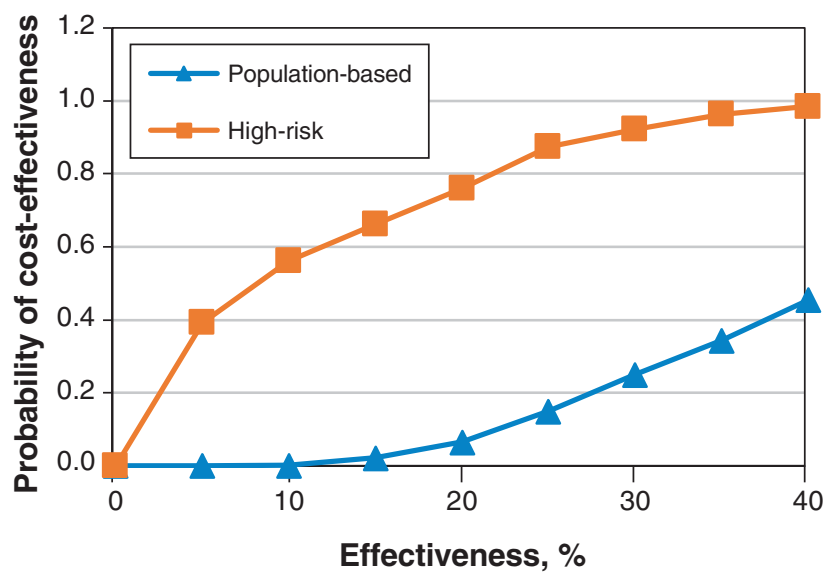

B

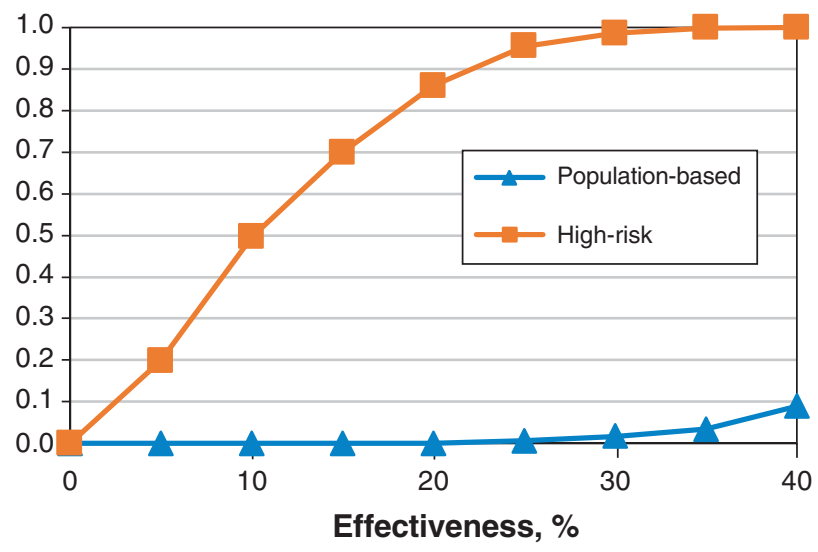

D

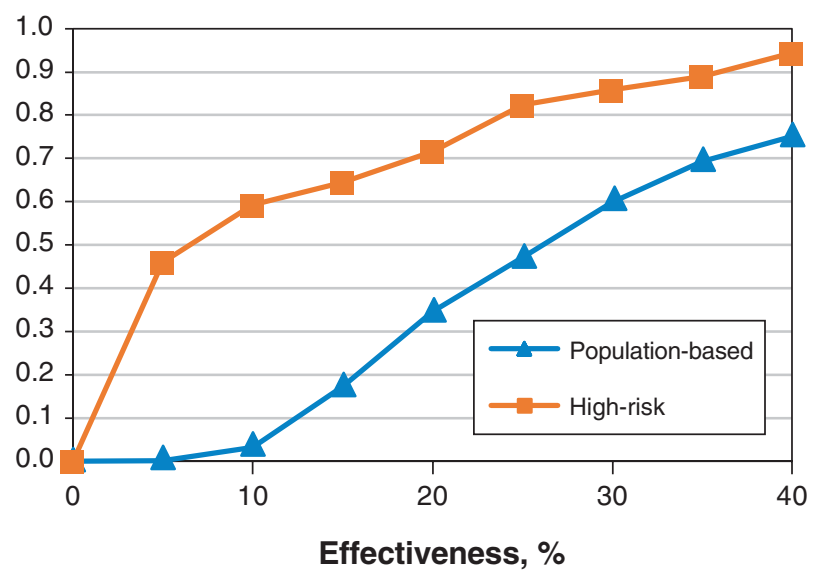

Figure 4: Varying the effectiveness of the telemedicine intervention influences the probability of cost-effectiveness at given willingness-to-pay thresholds. At a willingness-to-pay threshold of $\$ 0$ (A), \$20 000 (B) and $\$ 50000$ (C), the high-risk approach has a higher probability of costeffectiveness than the population-based approach. At a willingness-to-pay threshold of $\$ 100000$ (D) and effectiveness above $15 \%$, the population-based approach has a higher probability of cost-effectiveness than the high-risk approach.

\section{Interpretation}

In this work, we sought to evaluate the health and economic effects of using telemedicine to prevent diabetic foot ulcers. Although the absolute effect of telemedicine-based screening on ulcer incidence is unknown without clinical data, the potential health benefit associated with population-based screening was appreciable, ranging from 0.00399 to 0.00790 QALYs gained per person at a conservative effectiveness of $20 \%-40 \%$. For context, an increase in QALYs of 0.0032-0.0095 per person over a lifetime was reported for screening for hepatitis C in Canada. ${ }^{55}$ However, populationbased screening is a more widespread strategy than is currently in place in Canada and would result in incremental costs of \$479-\$402 (2015 dollars) per person over 5 years. In contrast, we found that using telemedicine following a patient's first ulcer had a high probability of being costeffective while also slightly increasing quality of life
(0.000207-0.00058 QALYs gained per person; decreased costs of $\$ 1.26-\$ 25.55$ per person at $15 \%-40 \%$ effectiveness). Cost savings were due to a reduction in ulcer recurrence and complications. Fewer screening devices are required in the high-risk approach (reducing upfront costs to the health care system), and targeting a group of patients with higher chances of ulcer formation eliminates waste.

\section{Limitations}

Our analysis was based on data from various sources, but there is a lack of data on the prevalence of diabetic foot ulcer and associated costs in Canada. We used conservative estimates for ulcer incidence to avoid inflated results, and therefore our models may have underestimated the impact of telemedicine. ${ }^{39}$ In addition, we sourced the utility value for a healed ulcer from a different study than that for the other health states, as Beaudet and colleagues ${ }^{48}$ did not report such value. This uncertainty may increase or decrease the impact of 
telemedicine (see 1-way analysis in Supplementary Figures A1 and A2, Appendix 1). Moreover, costing data available for this study do not encompass all costs associated with ulcers. For example, costs of the "ulcer state" in our model included only the cost of physician services and hospital-based acute care. However, not all ulcers are treated on an inpatient basis. Including outpatient clinic and home care costs would likely result in greater cost-effectiveness, but data in these realms of patient care are not available. Furthermore, indirect costs from a societal perspective, such as loss of productivity ${ }^{56}$ and travel costs incurred by the patient, were not included.

Our models represent simplified representations of diabetic foot ulcers and do not include the potential for infection or surgical débridement. ${ }^{3}$ It is unknown how this would change our results. Furthermore, our cohort was based on observational studies with an average patient age of 60 years. However, foot ulcers occur in patients with diabetes across all age groups ${ }^{57}$ Lower rates of ulcer incidence would increase ICERs, and higher rates would improve ICERs. Subgroup analyses should be explored in future studies. This analysis should be considered an early health technology assessment given the lack of important data on various parameters. The findings, however, represent an initial piece of evidence supporting a potential solution to a growing problem.

\section{Conclusion}

Rising rates of diabetes have been likened to an impending global tsunami. ${ }^{29}$ Health care systems must find a way to refocus care away from the reactionary and turn toward prevention. The use of telemedicine in the diabetic lower extremity can be an economically attractive alternative to current screening practices in Canada. Future work should focus on developing and validating technologies based on objective outcome measures for remote telemedicine of the diabetic foot.

\section{References}

1. Siersma V, Thorsen H, Holstein PE, et al. Importance of factors determining the low health-related quality of life in people presenting with a diabetic foot ulcer: the Eurodiale study. Diabet Med 2013;30:1382-7.

2. Buckley CM, O'Farrell A, Canavan RJ, et al. Trends in the incidence of lower extremity amputations in people with and without diabetes over a five-year period in the Republic of Ireland. PLoS One 2012; 7:e41492.

3. Canadian Diabetes Association Clinical Practice Guidelines Expert Committee; Bowering K, Embil JM. Foot care. Can 7 Diabetes 2013;37(Suppl 1):S145-9.

4. Bus SA, van Netten JJ, Lavery LA, et al.; International Working Group on the Diabetic Foot. IWGDF guidance on the prevention of foot ulcers in at-risk patients with diabetes. Diabetes Metab Res Rev 2016;32(Suppl 1):16-24.

5. Singh N, Armstrong DG, Lipsky BA. Preventing foot ulcers in patients with diabetes. 7AMA 2005;293:217-28.

6. Diabetics care gaps and disparities in Canada. Ottawa: Canadian Institute for Health Information; 2009. Available: https://secure.cihi.ca/estore/productFamily. htm?pf=PFC1387\&lang=en\&media=0 (accessed 2017 Aug. 22).

7. Lysy Z. Prevention of diabetic foot ulcers: the bottlenecks in the pathway. Diabetic Foot Can 2014;2:38-40.

8. Barshes NR, Sigireddi M, Wrobel JS, et al. The system of care for the diabetic foot: objectives, outcomes, and opportunities. Diabet Foot Ankle 2013;4:21847.

9. Siminerio LM, Piatt G, Zgibor JC. Implementing the chronic care model for improvements in diabetes care and education in a rural primary care practice. Diabetes Educ 2005;31:225-34.

10. Corser $\mathrm{W}, \mathrm{Xu} \mathrm{Y}$. Facilitating patients' diabetes self-management: a primary care intervention framework. 7 Nurs Care Qual 2009;24:172-8.

11. Griffith ML, Siminerio L, Payne T, et al. A shared decision-making approach to telemedicine: engaging rural patients in glycemic management. $\mathcal{F}$ Clin Med 2016;5:103.
12. Bonoto BC, de Araújo VE, Godói IP, et al. Efficacy of mobile apps to support the care of patients with diabetes mellitus: a systematic review and metaanalysis of randomized controlled trials. FMIR Mhealth Uhealth 2017;5:e4.

13. Terry M, Halstead LS, O'Hare P, et al. Feasibility study of home care wound management using telemedicine. Adv Skin Wound Care 2009;22:358-64.

14. Ameen J, Coll AM, Peters M. Impact of tele-advice on community nurses' knowledge of venous leg ulcer care. 7 Adv Nurs 2005;50:583-94.

15. Vowden K, Vowden P. A pilot study on the potential of remote support to enhance wound care for nursing-home patients. 7 Wound Care 2013;22:481-8.

16. Dobke MK, Bhavsar D, Gosman A, et al. Pilot trial of telemedicine as a decision aid for patients with chronic wounds. Telemed 7 E Health 2008;14:245-9.

17. Santamaria N, Carville K, Ellis I, et al. The effectiveness of digital imaging and remote expert wound consultation on healing rates in chronic lower leg ulcers in the Kimberley region of Western Australia. Primary Intention 2004;12:62-70.

18. Finkelstein SM, Speedie SM, Demiris G, et al. Telehomecare: quality, perception, satisfaction. Telemed 7 E Health 2004;10:122-8.

19. Wilbright WA, Birke JA, Patout CA, et al. The use of telemedicine in the management of diabetes-related foot ulceration: a pilot study. Adv Skin Wound Care 2004;17:232-8.

20. Rasmussen BSB, Froekjaer J, Bjerregaard MR, et al. A randomized controlled trial comparing telemedical and standard outpatient monitoring of diabetic foot ulcers. Diabetes Care 2015;38:1723-9.

21. Muller M, David-Tchouda S, Margier J, et al. Comment on Rasmussen et al. A randomized controlled trial comparing telemedical and standard outpatient monitoring of diabetic foot ulcers. Diabetes Care 2016;39:e9-10.

22. Chanussot-Deprez C, Contreras-Ruiz J. Telemedicine in wound care: a review. Adv Skin Wound Care 2013;26:78-82.

23. Sood A, Granick MS, Trial C, et al. The role of telemedicine in wound care: a review and analysis of a database of 5,795 patients from a mobile woundhealing center in Languedoc-Roussillon, France. Plast Reconstr Surg 2016;138 (Suppl):248S-56S.

24. Vyas KS, Hambrick HR, Shakir A, et al. A systematic review of the use of telemedicine in plastic and reconstructive surgery and dermatology. Ann Plast Surg 2017;78:736-68

25. Hazenberg CEVB, van Netten JJ, Van Baal JG, et al. Assessment of signs of foot infection in diabetes patients using photographic foot imaging and infrared thermography. Diabetes Technol Ther 2014;16:370-7.

26. Goyal M, Reeves ND, Rajbhandari S, et al. Fully convolutional networks for diabetic foot ulcer segmentation. Ithaca (NY): Cornell University Library; (preprint; v. 1, 2017 Aug. 6). Available: https://arxiv.org/abs/1708.01928 (accessed 2017 Aug. 18).

27. Armstrong DG, Holtz-Neiderer K, Wendel C, et al. Skin temperature monitoring reduces the risk for diabetic foot ulceration in high-risk patients. $A m \mathcal{F}$ Med 2007;120:1042-6.

28. Roglic G. Global report on diabetes: a summary. Geneva: World Health Organization; 2016.

29. An economic tsunami: the cost of diabetes in Canada. Toronto: Canadian Diabetes Association; 2009.

30. Hopkins RB, Burke N, Harlock J, et al. Economic burden of illness associated with diabetic foot ulcers in Canada. BMC Health Serv Res 2015;15:13.

31. Yazdanpanah L, Nasiri M, Adarvishi S. Literature review on the management of diabetic foot ulcer. World 7 Diabetes 2015;6:37-53.

32. Hinchliffe RJ, Brownrigg JRW, Apelqvist J, et al.; International Working Group on the Diabetic Foot. IWGDF guidance on the diagnosis, prognosis and management of peripheral artery disease in patients with foot ulcers in diabetes. Diabetes Metab Res Rev 2016;32(Suppl 1):37-44.

33. van Netten JJ, Price PE, Lavery LA, et al.; International Working Group on the Diabetic Foot. Prevention of foot ulcers in the at-risk patient with diabetes: a systematic review. Diabetes Metab Res Rev 2016;32(Suppl 1):84-98.

34. Hoogeveen RC, Dorresteijn JAN, Kriegsman DMW, et al. Complex interventions for preventing diabetic foot ulceration. Cocbrane Database Syst Rev 2015; (8):CD007610.

35. Guidelines for the economic evaluation of health technologies: Canada. 4th ed. Ottawa: Canadian Agency for Drugs and Technologies in Health; 2017.

36. Husereau D, Drummond M, Petrou S, et al.; ISPOR Health Economic Evaluation Publication Guidelines-CHEERS Good Reporting Practices Task Force. Consolidated Health Economic Evaluation Reporting Standards (CHEERS) - explanation and elaboration: a report of the ISPOR Health Economic Evaluation Publication Guidelines Good Reporting Practices Task Force. Value Health 2013;16:231-50.

37. Botros M, Kuhnke J, Embil J, et al. Best practice recommendations for the prevention and management of diabetic foot ulcers. North York (ON): Wounds Canada (Canadian Association of Wound Care); (2018 Jan. 24). Available: https://www.woundscanada.ca/docman/public/health-care -professional/bpr-workshop/895-wc-bpr-prevention-and-management-of -diabetic-foot-ulcers-1573r1e-final/file (accessed 2017 May 15).

38. Zimny S, Schatz H, Pfohl M. Determinants and estimation of healing times in diabetic foot ulcers. 7 Diabetes Complications 2002;16:327-32.

39. Lavery LA, Peters EJ, Williams JR, et al.; International Working Group on the Diabetic Foot. Reevaluating the way we classify the diabetic foot: restructuring the diabetic foot risk classification system of the International Working Group on the Diabetic Foot. Diabetes Care 2008;31:154-6. 
40. Armstrong DG, Boulton AJM, Bus SA. Diabetic foot ulcers and their recurrence. $N$ Engl 7 Med 2017;376:2367-75.

41. Dubský M, Jirkovská A, Bem R, et al. Risk factors for recurrence of diabetic foot ulcers: prospective follow-up analysis in the Eurodiale subgroup. Int Wound 7 2013;10:555-61.

42. Prompers L, Schaper N, Apelqvist J, et al. Prediction of outcome in individuals with diabetic foot ulcers: focus on the differences between individuals with and without peripheral arterial disease. The Eurodiale Study. Diabetologia 2008;51: 747-55.

43. Örneholm H, Apelqvist J, Larsson J, et al. Recurrent and other new foot ulcers after healed plantar forefoot diabetic ulcer. Wound Repair Regen 2017;25: 309-15.

44. Moulik PK, Mtonga R, Gill GV. Amputation and mortality in new-onset diabetic foot ulcers stratified by etiology. Diabetes Care 2003;26:491-4.

45. Morbach S, Furchert H, Gröblinghoff U, et al. Long-term prognosis of diabetic foot patients and their limbs: amputation and death over the course of a decade. Diabetes Care 2012;35:2021-7.

46. Oyibo SO, Jude EB, Tarawneh I, et al. The effects of ulcer size and site, patient's age, sex and type and duration of diabetes on the outcome of diabetic foot ulcers. Diabet Med 2001;18:133-8.

47. Aulivola B, Hile CN, Hamdan $\mathrm{AD}$, et al. Major lower extremity amputation: outcome of a modern series. Arch Surg 2004;139:395-9.

48. Beaudet A, Clegg J, Thuresson PO, et al. Review of utility values for economic modeling in type 2 diabetes. Value Health 2014;17:462-70.

49. Redekop WK, Stolk E, Kok E, et al. Diabetic foot ulcers and amputations: estimates of health utility for use in cost-effectiveness analyses of new treatments. Diabetes Metab 2004;30:549-56.

50. Schedule of benefits: physician services under the Health Insurance Act. Toronto: Ministry of Health and Long-Term Care; 2016. Available: www.health.gov. on.ca/en/pro/programs/ohip/sob/physserv/sob_master20151221.pdf (accessed 2017 June 14).

51. Patient cost estimator: methodological notes and glossary. Ottawa: Canadian Institute for Health Information; 2016.

52. Fasterholdt I, Gerstrøm M, Rasmussen BSB, et al. Cost-effectiveness of telemonitoring of diabetic foot ulcer patients. Health Informatics 7 2018;24:245-58

53. Financial statements: Ontario Telemedicine Network. Toronto: Ernst \& Young; 2016 Mar. 31. Available: https://otn.ca/wp-content/uploads/2016/10/ otn-audited-financial-statements-2015-2016.pdf (accessed 2017 July 10).
54. Briggs A, Sculpher M, Claxton K. Decision modelling for bealth economic evaluation. Oxford (UK): Oxford University Press; 2006.

55. Wong WWL, Tu HA, Feld JJ, et al. Cost-effectiveness of screening for hepatitis C in Canada. CMA7 2015;187:E110-21.

56. Highlights: diabetes in Canada - facts and figures from a public health perspective. Ottawa: Public Health Agency of Canada; (modified 2011 Dec. 15). Available: www.phac-aspc.gc.ca/cd-mc/publications/diabetes-diabete/facts -figures-faits-chiffres-2011/highlights-saillants-eng.php (accessed 2017 May 10).

57. Margolis DJ, Malay DS, Hoffstad OJ, et al. Incidence of diabetic foot ulcer and lower extremity amputation among Medicare beneficiaries, 2006 to 2008: data points \#2. Rockville (MD): Agency for Healthcare Research and Quality; 2011. Available: www.ncbi.nlm.nih.gov/books/NBK65149/ (accessed 2017 Aug. 1).

Affiliations: Department of Medical Imaging (Boodoo, Leung), Division of Plastic Surgery (Perry, Cross), Centre for Excellence in Economic Analysis Research (Isaranuwatchai) and Keenan Research Centre for Biomedical Science (Leung, Cross), St. Michael's Hospital; Institute of Health Policy, Management and Evaluation (Isaranuwatchai), University of Toronto, Toronto, Ont.

Contributors: Chris Boodoo, General Leung and Wanrudee Isaranuwatchai conducted the analyses. Chris Boodoo, Julie Perry and Wanrudee Isaranuwatchai drafted the manuscript. Chris Boodoo, General Leung, Julie Perry and Wanrudee Isaranuwatchai interpreted the data. Julie Perry critically revised the manuscript for important intellectual content. All of the authors contributed to the conception and design of the study, gave final approval of the version to be published and agreed to be accountable for all aspects of the work.

Funding: This study was supported by grants from the Canadian Institutes of Health Research (PJT-148783) and the St. Michael's Foundation Translation Innovation Fund.

Supplemental information: For reviewer comments and the original submission of this manuscript, please see www.cmajopen.ca/content/6/4/ E486/suppl/DC1. 